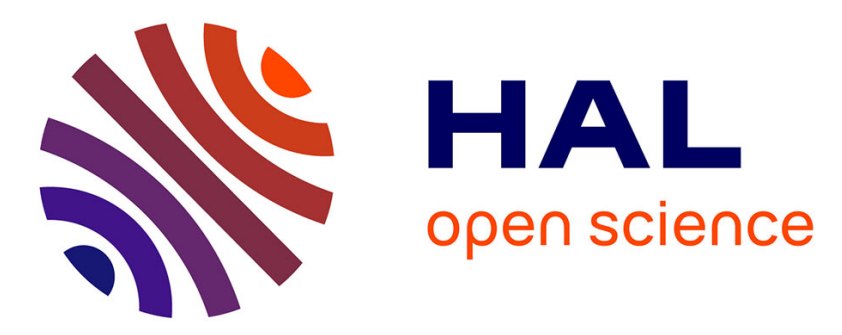

\title{
Assessment of empirical potential for MOX nuclear fuels and thermomechanical properties
}

Hector Balboa, Laurent van Brutzel, Alain Chartier, Yann Le Bouar

\section{To cite this version:}

Hector Balboa, Laurent van Brutzel, Alain Chartier, Yann Le Bouar. Assessment of empirical potential for MOX nuclear fuels and thermomechanical properties. Journal of Nuclear Materials, 2017, 495, pp.67-77. 10.1016/j.jnucmat.2017.07.067 . hal-01632412

\section{HAL Id: hal-01632412 \\ https://hal.science/hal-01632412}

Submitted on 5 Jul 2021

HAL is a multi-disciplinary open access archive for the deposit and dissemination of scientific research documents, whether they are published or not. The documents may come from teaching and research institutions in France or abroad, or from public or private research centers.
L'archive ouverte pluridisciplinaire HAL, est destinée au dépôt et à la diffusion de documents scientifiques de niveau recherche, publiés ou non, émanant des établissements d'enseignement et de recherche français ou étrangers, des laboratoires publics ou privés. 


\title{
Assessment of empirical potential for MOX nuclear fuels and thermomechanical properties
}

\author{
Hector Balboa $^{\mathrm{a}}$, Laurent Van Brutzel ${ }^{\mathrm{a}, *}$, Alain Chartier ${ }^{\mathrm{a}}$, Yann Le Bouar ${ }^{\mathrm{b}}$ \\ ${ }^{a}$ Den-Service de la Corrosion et du Comportement des Matériaux dans leur Environnement (SCCME), CEA, Université Paris-Saclay, F-91191, Gif-sur-Yvette, \\ France \\ ${ }^{b}$ Lab. d'Étude des Microstructures, CNRS-ONERA, 29, avenue de la division Leclerc, BP 72, 92322, Châtillon, France
}

\begin{abstract}
We assess five empirical interatomic potentials in the approximation of rigid ions and pair interactions for the $\left(\mathrm{U}_{1-y}, \mathrm{Pu}_{y}\right) \mathrm{O}_{2}$ solid solution. The assessment compares available experimental data and Fink's recommendation with simulations on: the structural, thermodynamics, and mechanical properties over the full range of plutonium composition, from pure $\mathrm{UO}_{2}$ to $\mathrm{pure}^{\mathrm{PuO}} \mathrm{O}_{2}$ and for temperatures ranging from $300 \mathrm{~K}$ to the melting point. The best results are obtained by potentials referred as Cooper and Potashnikov potentials. The first one reproduces more accurately recommendations for the thermodynamics and mechanical properties exhibiting ductile-like behaviour during crack propagation, while the second one gives brittle behaviour at low temperature.
\end{abstract}

Keywords: Molecular dynamics, nuclear fuel, mechanical, assessment

\section{Introduction}

Nowadays, uranium dioxide $\left(\mathrm{UO}_{2}\right)$ is being used as the standard nuclear fuel in fission nuclear reactors and has been extensively studied since the sixties. In parallel, nuclear fuel containing a mixture of uranium and plutonium oxides (MOX) as principle components provides an alternative, due to the fact that: (1) it allows large quantities of fissile isotopes produced in spent nuclear fuel from light water reactors to be recycled, (2) it can be seen as a more efficiently way of using the uranium dioxide, since the abundant ${ }^{238} \mathrm{U}$ found in natural uranium is a $\mathrm{Pu}$ producer, (3) it can be taken as a solution for the increasing stockpile of $\mathrm{Pu}$ around the globe coming from either nuclear weapons and commercial reactors, and (4) it is designated as the most probable fuel for future fast breeder reactors, such as ASTRID (Advanced Sodium Technological Reactor for Industrial Demonstration).

A very important issue for the future of nuclear power is to ensure safeness and effectiveness during processes involving MOX fuel such as fabrication, operation and recycling. Yet, the toxicity of plutonium and high radiation levels make experiments less viable. Nonetheless, beside previous experimental efforts gathered in the following reviews [1,2], experiments with MOX are difficult to perform, especially at high temperatures and under irradiation condition. For these reasons, numerical approaches can be chosen to bring some insight on basic physical phenomena that take place in the fuel matrix. For instance, over the last decade, several atomistic approaches using molecular dynamics (MD) simulations have been carried out to study thermal conductivity properties in $(\mathrm{U}, \mathrm{Pu}) \mathrm{O}_{2}$ [3-12].

${ }^{*}$ Corresponding author. Tel.: +33-1 690879 15; Fax: +33-1 69089221

Email address: laurent.vanbrutzel@cea.fr (Laurent Van Brutzel)
However, the reliability of the results depends exclusively on the choice of the set of potentials. The potential parameters are usually fitted to reproduce a few physical properties, typically the lattice parameter, the cohesive energy, and complementary the elastic constants, which comes from experimental values or if not available from $a b$ initio calculations. Therefore, each potential has its domain of validity. Subsequently, others physical properties for which the set of parameters are not been fitted need to be assessed to provide a good insight of advantages and disadvantages of each potential and their range of validity. This type of study has already been carried out in the case of $\mathrm{UO}_{2}$ [13-16] but, to our knowledge, not yet for MOX. Therefore, in this study, we assess available rigid ion model empirical potentials for MOX on the structural, thermodynamics, and mechanical properties. The assessment is performed over the full range of plutonium composition, from pure $\mathrm{UO}_{2}$ to pure $\mathrm{PuO}_{2}$ and for temperatures ranging from $300 \mathrm{~K}$ to melting point.

With MD method, actinide atoms are usually simulated in the approximation of rigid ions and pair interactions. For the mixed oxide compound $(\mathrm{U}, \mathrm{Pu}) \mathrm{O}_{2}$, several interatomic potentials are available in the literature. There exists two main families of potentials. One that considers $\mathrm{U}$ and $\mathrm{Pu}$ cations as one single entity and hence they include only three set of parameters (A$\mathrm{A}, \mathrm{A}-\mathrm{O}$, and $\mathrm{O}-\mathrm{O})$ but depends on the relative percentage of $\mathrm{Pu}$ in the MOX [17]. The second one treats explicitly the $U$ and $\mathrm{Pu}$ cations. Therefore, they include six set of parameters (U$\mathrm{U}, \mathrm{U}-\mathrm{Pu}, \mathrm{Pu}-\mathrm{Pu}, \mathrm{U}-\mathrm{O}, \mathrm{Pu}-\mathrm{O}$, and $\mathrm{O}-\mathrm{O}$ ) and do not depend on the percentage of $\mathrm{Pu}$. Because we are interested in studying the spatial repartition of both cation and anion sublattices, we will only consider and describe the second type of force field.

Five rigid ion model potentials have been found in the literature and are tested herein. They will be coined by the name of the first author: Yamada [3], Arima [6], Potashnikov [15], 
Tiwary [18], and Cooper [19, 20]. We will present first the method used, then we will discuss the results obtained for the lattice parameter, the thermal expansion, the specific heat capacity, the elastic constants, the stress-strain curves under uniaxial deformation, and crack propagation.

\section{Computational method}

These five force fields can be separated according the properties on which they have been fitted. All potentials have been fitted to reproduce correctly the thermal expansion up to the maximum temperature available by experiments at the time, which is about 2100 K. Historically, Yamada was the first one followed by Arima and Potashnikov with some improvement at high temperature, up to the melting point. Tiwary potential includes also fits on the formation energy of point defects (Frenkel pairs), while the Cooper potential focuses on reproducing accurately the mechanical behaviour and has been fitted on experimental data for single crystal elastic constants.

However, the Tiwary potential, did not provide a stable fluorite structure for either $\mathrm{UO}_{2}$ nor $\mathrm{PuO}_{2}$ using finite temperature MD simulations. Nevertheless it gives good results using static calculations $(0 \mathrm{~K})$. Therefore, we drop this potential from our assessment.

The four remaining potentials are described with classical short-range (Buckingham and Morse) and long-range (van der Waals and Coulomb) interactions (see Eq. 1). Table 1 presents the forms of the four potentials.

$U_{\alpha \beta}(r)=A_{\alpha \beta} e^{-r / \rho_{\alpha \beta}}-\frac{C_{\alpha \beta}}{r^{6}}+D_{\alpha \beta}\left[e^{-2 \gamma_{\alpha \beta}\left(r-r_{0}\right)}-2 e^{-\gamma_{\alpha \beta}\left(r-r_{0}\right)}\right]+\frac{q_{\alpha} \cdot q_{\beta}}{4 \pi \epsilon_{0} r}$

where $A_{\alpha \beta}, C_{\alpha \beta}, D_{\alpha \beta}, \gamma_{\alpha \beta}, q_{\alpha}$ and $r_{0}$ are parameters whose values are given in Table 2. The first term in Eq. 1 is designed to reproduce the repulsion originating from the Pauli's exclusion principle. The second term is the attractive van der Waals' interaction. The third term (Morse) is designed to describe more accurately covalent bond and the vibrations in molecules. Finally, the last term represents the long-range Coulomb interaction.

For the Cooper potential, an EAM (Embedded Atom Model) many-body term is added (Eq. 2 and Eq. 3), in order to reproduce the Cauchy's violation observed in actinide oxides with the fluorite structure (i.e. $C_{12} \neq C_{44}$ ) [21], which cannot be reproduced by only pair-wise potentials.

$$
E_{i}^{\mathrm{EAM}}=-G_{\alpha} \sqrt{\sum_{j \neq i} \sigma_{\beta}\left(r_{i j}\right)}
$$

where, $\sigma_{\beta}$ is computed as follow:

$$
\sigma_{\beta}\left(r_{i j}\right)=\frac{1}{2}\left(\frac{\eta_{\beta}}{r_{i j}^{8}}\right)\left\{1+\operatorname{erf}\left[20\left(r_{i j}-1.5\right)\right]\right\} .
$$

erf stands for the error function and $\eta_{\beta}$ is a parameter. Tables 3 provides the EAM Cooper potential parameters.
Table 1: Type of physical function for the different interatomic potentials studied.

\begin{tabular}{lcccc}
\hline \hline Potential & Coulomb & Buckingham & Morse & EAM \\
\hline Yamada & $\checkmark$ & $\checkmark$ & $\checkmark$ & \\
Arima & $\checkmark$ & $\checkmark$ & & \\
Potashnikov & $\checkmark$ & $\checkmark$ & & \\
Cooper & $\checkmark$ & $\checkmark$ & $\checkmark$ & $\checkmark$ \\
\hline \hline
\end{tabular}

In this study, we will compare systematically via MD simulations structural properties (lattice parameter, thermal expansion), thermodynamic properties (heat capacity, enthalpy), and mechanical properties (elastic constants, stress-strain curves) for the four empirical potentials remaining over temperatures ranging from $300 \mathrm{~K}$ to the melting point $(\sim 3000 \mathrm{~K})$ and for compounds from pure $\mathrm{UO}_{2}$ to pure $\mathrm{PuO}_{2}$.

The whole study was carried out using the code LAMMPS [22]. Most of the assessment requires relatively small system sizes: about $7 \times 7 \times 7$ fluorite structure unit cells involving 4116 atoms. Moreover, it ensures enough statistics for the different configurations. For the crack propagation, the size of the box is increased to $440 \times 110 \times 7$ fluorite structure unit cells. In all the cases we are using periodic boundary conditions to avoid surface effects. The Coulomb interactions are calculated with the full Ewald summation procedure. The relaxation is done under NPT thermodynamic ensemble using the well-known Parrinello-Rahman's algorithm [23]. The systems are relaxed $100 \mathrm{ps}$ and all the thermodynamic properties are averaged over the last 20 ps.

Since the force fields are based on rigid ion model, it is not possible to study none stoichiometric compounds. Therefore, we can consider the $\left(\mathrm{U}_{1-y} \mathrm{Pu}_{y}\right) \mathrm{O}_{2}$ compound as a continuous solid solution as shown by the assessment of Belin et al. [24]. The plutonium atoms are then distributed randomly in the unit cell on the a-Wyckoff sites (fluorite-like cation sites). The plutonium concentration ranges from 0 to 100 at.\% with mainly 15 at.\% steps. However, for clarity most of the figures presented herein will only display compounds containing 0,25 , 75 , and 100 at.\% of plutonium atoms or in some cases it will only be shown for the most relevant case.

\section{Results and discussion}

\subsection{Lattice parameter}

The first structural property to fit is the evolution of the lattice parameter with the temperature. Therefore, all the interatomic potentials studied should fit more or less the experimental results. However, Yamada and Arima fitted their potential only up to $2100 \mathrm{~K}$, whereas Potashnikov and Cooper fitted their potential with values up to $2900 \mathrm{~K}$. It is worth to mention that experimental data are really sensitive to the $\mathrm{O} / \mathrm{U}$ ratio hence we keep our comparison with the strict stoichiometric compound. Furthermore, experimental works are scarcely available at high temperatures (close to the melting point), thus it is difficult to estimate the statistical dispersion for these temperatures. 
Table 2: Parameters for the interatomic potentials.

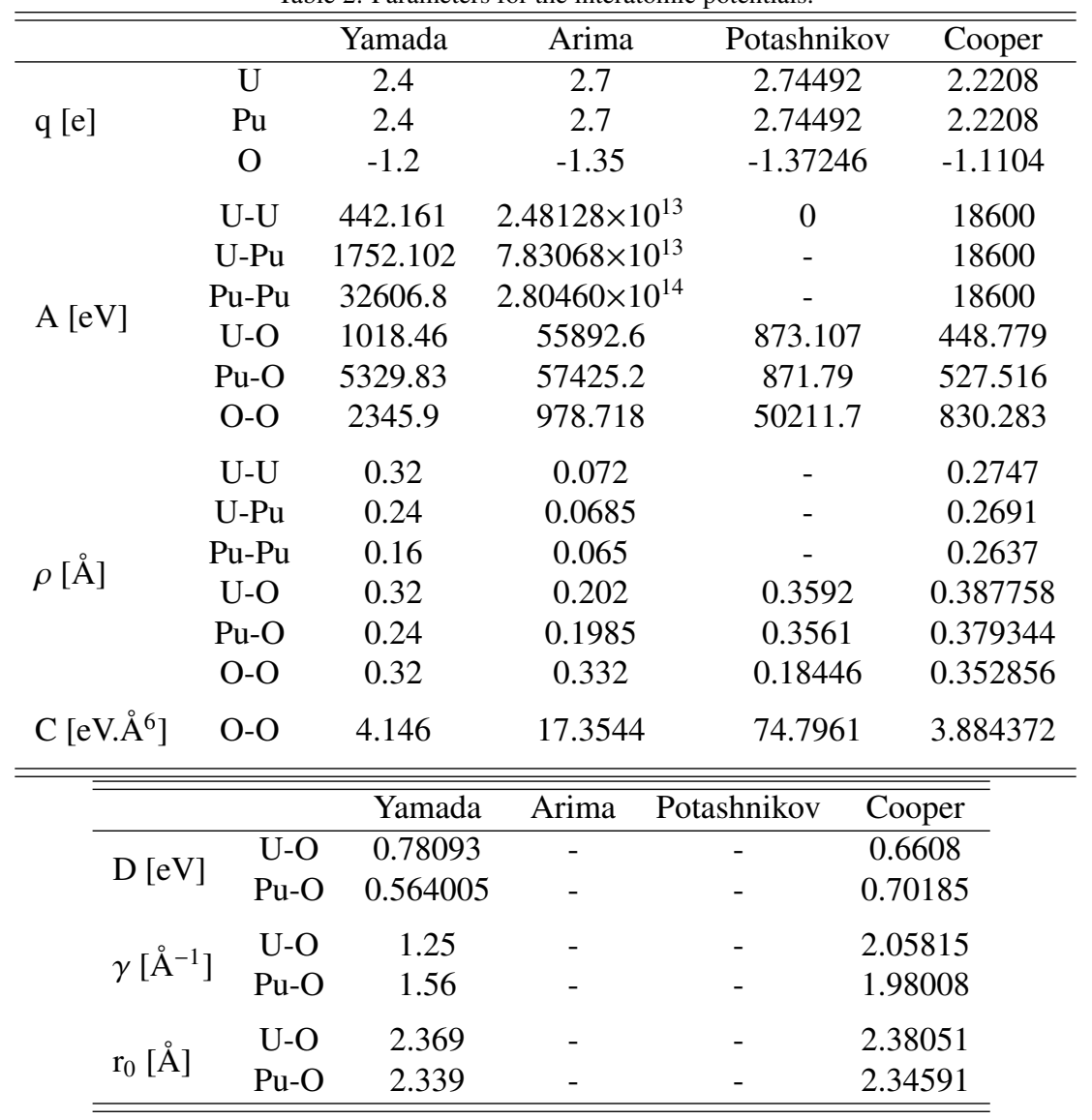


Table 3: Parameters for Cooper EAM term

\begin{tabular}{lcc}
\hline \hline & $\mathrm{G}_{\alpha}\left[\mathrm{eV} . \AA^{1.5}\right]$ & $\eta_{\beta}\left[\AA^{5}\right]$ \\
\hline $\mathrm{U}$ & 1.806 & 3450.995 \\
$\mathrm{Pu}$ & 2.168 & 3980.058 \\
$\mathrm{O}$ & 0.69 & 106.856 \\
\hline \hline
\end{tabular}

As expected, the changes in the calculated lattice parameters for pure $\mathrm{UO}_{2}$ as a function of temperature for all potentials are in good agreement with experimental data [25] and Fink's recommendations [26] up to $2100 \mathrm{~K}$ (not shown).

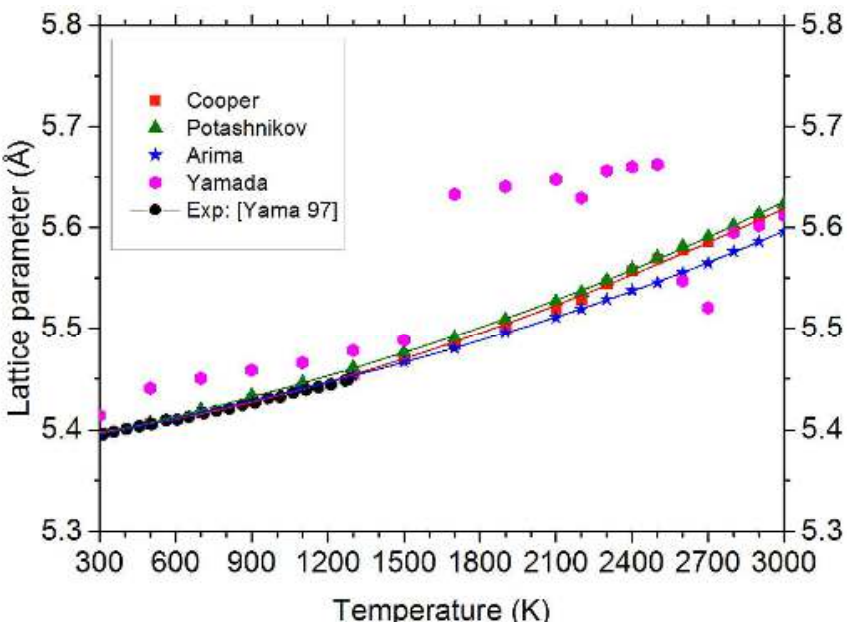

Figure 1: Evolution of the lattice parameter as a function of the temperature for the four potentials studied for pure $\mathrm{PuO}_{2}$. The results are compared with Yamashita's experimental work (Yama 97 [25]).

We have performed a similar comparison for pure $\mathrm{PuO}_{2}$ and the result is presented in Fig. 1. Cooper, Potashnikov, and Arima potentials fit relatively well the experimental data up to $1300 \mathrm{~K}$. For temperatures higher than $2100 \mathrm{~K}$, Arima potential underestimates consistently the recommendation lattice parameters. On the other hand, Yamada potential shows a large discrepancy with no continuous evolution for the full range of temperature. This behaviour has already been pointed out by Potashnikov et al. in their potential assessment [15]. With the Yamada potential, a phase transition from fluorite to rutile-like structure occurs spontaneously for $\mathrm{PuO}_{2}$ at high temperatures. This demonstrates that for Yamada potential this new phase is more stable than the fluorite structure contrary to experiments [27]. Therefore, this potential is not considered for the following study.

The evolution of the lattice parameters as a function of the temperature for each potential, excluding Yamada's due to the anomalies discussed above, with respect of the plutonium content is similar than for the pure compounds. Hence, we can fit MD data with a general expression of the form: $a(T, y)=$ $A T^{3}+B T^{2}+C T+D+m y$, where $y$ denotes the plutonium content $(0<\mathrm{y}<1)$ and $T$ is the temperature $(300 \mathrm{~K}$ to melting point). The parameters are reported in Table 4 . The percentage of difference with Fink's recommendation for pure $\mathrm{UO}_{2}(\mathrm{y}=0)$ is less than $1 \%$ for all remaining potentials, which denotes a good structural evolution of the potentials.

Table 4: Parameters for the third degree polynomial that fits the evolution of the lattice parameters as the function of temperature and plutonium content.

\begin{tabular}{lccccc}
\hline \hline & $\mathrm{A}\left[\AA . \mathrm{K}^{-3}\right]$ & $\mathrm{B}\left[\AA . \mathrm{K}^{-2}\right]$ & $\mathrm{C}\left[\AA . \mathrm{K}^{-1}\right]$ & $\mathrm{D}[\AA]$ & $\mathrm{m}[\AA]$ \\
\hline Arima & $1.03 \times 10^{-12}$ & $3.89 \times 10^{-9}$ & $4.99 \times 10^{-5}$ & 5.450 & -0.074 \\
Potashnikov & $1.80 \times 10^{-12}$ & $1.82 \times 10^{-9}$ & $6.12 \times 10^{-5}$ & 5.441 & -0.065 \\
Cooper & $1.90 \times 10^{-12}$ & $2.82 \times 10^{-9}$ & $5.16 \times 10^{-5}$ & 5.453 & -0.072 \\
\hline \hline
\end{tabular}

We also check if the lattice parameter evolves as the Vegard's law for stoichiometric MOX compounds up to the melting point. This behaviour has been verified experimentally up to $2000 \mathrm{~K}[1,2]$. The percentage of deviation from Vegard's law as function of temperature for compounds with different plutonium contents behaves similarly for all potentials. From 300 to $\sim 2500 \mathrm{~K}$ the Vegard's law is verified within $\pm 0.02 \%$. From $2500 \mathrm{~K}$ to the melting point, the Potashnikov and Cooper potentials significantly deviate from Vegard's law, whereas Arima potential seems to follow Vegard's law for the full temperature range. The discrepancy with Potashnikov and Cooper potentials is usually attributed to a high sublattice oxygen disorder (see next chapter for more details).

\subsection{Thermal expansion coefficients}

A more sensitive quantity to evaluate the structural property with temperature is the linear thermal expansion coefficient (LTEC). This coefficient is calculated as the first derivative of the lattice parameter with respect to the temperature using the following expression:

$$
\alpha(T)=\frac{1}{a_{0}}\left(\frac{\partial a}{\partial T}\right)_{P}
$$

where, $a_{0}$ denotes, in our cas,e the lattice parameter at $300 \mathrm{~K}$, and $(\partial a / \partial T)_{P}$ is the first derivative at constant pressure calculated by numerical differentiation from the lattice parameter evolution. Fig. 2 displays the LTEC with Cooper (C ending), Potashnikov ( $\mathrm{P}$ ending) and Arima (A ending) potentials for different plutonium contents $(0<y<1)$. These values are compared to Uchida's experimental data for pure $\mathrm{PuO}_{2}$ [28] and Fink's recommendation for pure $\mathrm{UO}_{2}$ up to $2000 \mathrm{~K}$.

As expected, the LTEC follows the experimental data and the recommendation from 300 to $2000 \mathrm{~K}$. There is also no noticeable difference with the plutonium content for this range of temperature. After $2000 \mathrm{~K}$, peaks appear for Potashnikov and Cooper potentials. For Cooper potential they depend on the plutonium content as previously mentioned [20]. These peaks, referred to as $\lambda$-peak, were discovered and characterized by Bredig et al. for most of the fluorite-like structures [29] and can be attributed to a diffusing phase transition that turns compounds into a superionic conductor. Several reviews of experimental works $[30,31]$ and theoretical works [15, 20, 32-34] show that this transition occurs around $0.8 T_{m}$, where $T_{m}$ is the melting temperature. It is often associated with premelting of the oxygen sublattice. 


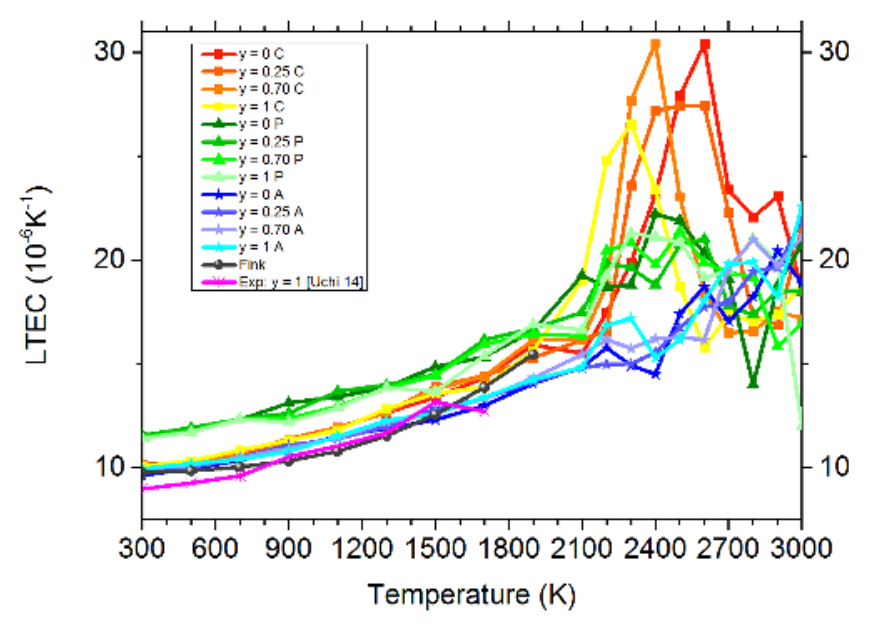

Figure 2: Evolution of the linear thermal expansion coefficient obtained for different plutonium contents as a function of temperature (the value of $y$ indicates the plutonium content, $\left.\left(\mathrm{U}_{1-y} \mathrm{Pu}_{y}\right) \mathrm{O}_{2}\right)$. Arima potential (A ending) is referred with blueish colours and star symbols, Potashnikov potential ( $\mathrm{P}$ ending) is referred with greenish colours and triangle symbols, and Cooper potential (C ending) is referred with reddish colours and square symbols.

For the Cooper potential, as already stated by the authors [20], the $\lambda$-peak for pure $\mathrm{UO}_{2}$ occurs around $2600 \mathrm{~K}$ in concordance with the experimental value of superionic transition temperature of $2670 \mathrm{~K}$ [35]. For the case of pure $\mathrm{PuO}_{2}$, there is no experimental data available which could confirm the existence of a superionic transition. However, according to the theory of $0.8 T_{m}$, it should occur around $2400 \mathrm{~K}$ since the melting temperature in $\mathrm{PuO}_{2}$ was recently measured at $3040 \mathrm{~K}$ [36]. Therefore, the superionic transition temperature of $2300 \mathrm{~K}$ found with the Cooper potential for $\mathrm{PuO}_{2}$ is maybe slightly underestimated but still in the range. Moreover, $\lambda$-peaks decreases with the increase of the plutonium content, which is in agreement with previous studies [20].

In the case of the Potashnikov potential, the values from 300 to $2000 \mathrm{~K}$ are slightly higher than the experimental data and the recommendation. The $\lambda$-peaks are present but less pronounced than for the Cooper potential. Due to the lack of statistics with our results, no clear difference appears with plutonium content. Finally, for the Arima potential, like for the two others, the LTEC behaves linearly up to $2000 \mathrm{~K}$. At higher temperatures, although there are small oscillations, no clear $\lambda$-peak can be noticed for all plutonium content up to $3000 \mathrm{~K}$. However, previous studies on pure $\mathrm{UO}_{2}[15]$ show a clear $\lambda$-peak with the Arima potential around $3500 \mathrm{~K}$. The melting point with this potential is found to be around $4500 \mathrm{~K}$, which overestimates the experimental data. Nevertheless, it still follows the theory of the $0.8 T_{m}$.

Overall, all potentials give a good estimation of the LTEC up to $2000 \mathrm{~K}$. Differences between potentials appear at higher temperatures, i.e. in condition for which the experimental data for $\mathrm{MOX}$ and $\mathrm{PuO}_{2}$ are lacking. It is then somehow difficult to choose the best potential, which reproduces most the real material. However, the behaviour according the superionic transition temperature can provide more indication. The Cooper poten- tial, gives a clear distinction between the superionic transition temperatures with the plutonium content and seems to follow best the theoretical $\lambda$-peak temperatures while the Potashnikov potential does not show significant change with the increase of the plutonium content. Finally, Arima potential reproduces no $\lambda$-peaks in the range of the temperatures studied.

\subsection{Enthalpy and specific heat}

We have calculated the enthalpy evolution as a function of temperature up to the melting point for Arima, Potashnikov, and Cooper potentials (not shown). The enthalpy values up to $2000 \mathrm{~K}$ are almost identical and fit perfectly the Fink's recommendation. Discrepancy appears at $2400 \mathrm{~K}$, where Arima potential still provides a linear feature, while Fink's recommendation and both the Potashnikov and Cooper potentials deviate from linearity. For these two last potentials discrepancy with Fink's recommendation appears around $2600 \mathrm{~K}$, which is the temperature of the $\lambda$-peak.

More noticeable changes can be extracted with the analysis of the specific heat. The specific heat capacity coefficients at constant pressure can be calculated directly by numerical differentiation from the enthalpy increment function with the following relationship:

$$
C_{\mathrm{P}}=\frac{1}{n}\left(\frac{\partial H}{\partial T}\right)_{P}
$$

where $n$ is the number of moles. All the evolutions of $C_{\mathrm{P}}$ as a function of temperature for different plutonium contents are shown in Fig. 3. The temperature range investigated herein is above the Debye temperatures calculated with the different potentials, which are between 350 and $480 \mathrm{~K}$. Overall, the behaviour is similar to that of the LTEC. However, $\lambda$-peaks appear more clearly than with the LTEC in the case of the Potashnikov potential even though no clear dependence with the plutonium content can be drawn. This demonstrates that this potential can also reproduce the superionic transition, as already been shown in the case of pure $\mathrm{UO}_{2}$ [15]. On the other hand, Arima potential seems not to include this transition up to $3000 \mathrm{~K}$.

\subsection{Elastic constants}

The assessment of the elastic constants as a function of temperature and plutonium content is important because the Potashnikov and Arima potentials were not fitted on those properties. Furthermore, the Cooper potentials has been fitted only with experimental data at room temperature. It is then an important checkpoint on the reliability of these potentials for further studies of the mechanical properties under irradiation. In addition, evolution of elastic properties with temperature in MOX is rather scarce in the literature, thus, atomic simulation could bring some insight in the subject.

The elastic constants, at finite temperature, are computed in a stepwise fashion. First, small deformations (0.1\%) are imposed on the box for all the six Voigt components of the strain tensor $\epsilon_{i}$. This step is followed by an equilibration at constant temperature and constant volume for 10 ps. Elastic moduli were then 


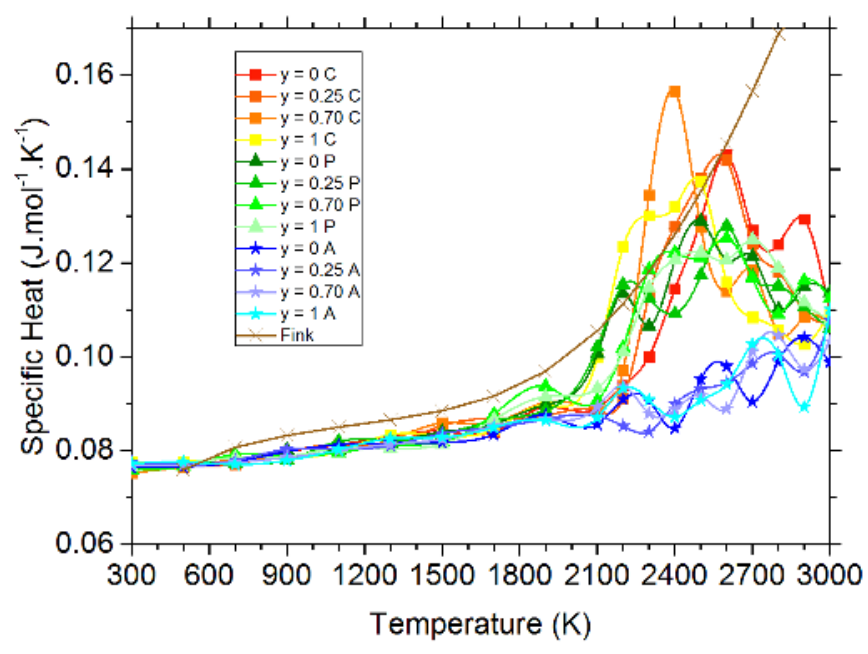

Figure 3: Evolution of the $C_{\mathrm{P}}$ as a function of the temperature for different plutonium contents (the value of $y$ indicates the plutonium content, $\left.\left(\mathrm{U}_{1-y} \mathrm{Pu}_{y}\right) \mathrm{O}_{2}\right)$. The same colour code than for the LTEC is used.

calculated as initial slopes of stress-strain curves obtained using appropriate components of stress and strain tensors. More specifically, the Young's modulus is deduced by applying tension and compression uniaxial strains individually and calculated as $\sigma_{i} / \epsilon_{i}$, where $\sigma_{i}$ are the components of the stress tensor.

The results that we have obtained with MD simulations will be compared to the recommendation based on the review of Martin et al. [37], who assesses experimental data from mainly polycrystalline materials. In this review, the authors concluded that the elastic constants of stoichiometric $(\mathrm{U}, \mathrm{Pu}) \mathrm{O}_{2}$ should be taken identical to those of $\mathrm{UO}_{2}$. Also, recommendation shows only the evolution of Young's and shear moduli. In consequence, we will compare computed Young's (noted E) and shear (noted G) moduli calculated from elastic stiffness tensor coefficients using the Voigt-Reuss-Hill approximation for randomly oriented polycrystals [38-40]. The equations to transform the elastic stiffness coefficients found in monocrystal into shear and Young's polycrystalline moduli for a cubic system are presented below:

$$
\begin{aligned}
G_{\text {polycrystal }} & =\left(G_{\text {Reuss }}+G_{\text {Voigt }}\right) / 2 \\
\text { with } G_{\text {Reuss }} & =\frac{5\left(C_{11}-C_{12}\right) C_{44}}{\left[4 C_{44}+3\left(C_{11}-C_{12}\right)\right]} \\
\text { and } \quad G_{\text {Voigt }} & =\left(C_{11}-C_{12}+3 C_{44}\right) / 5 \\
E_{\text {polycrystal }} & =\frac{-9 B G_{\text {polycrystal }}}{\left(3 B+G_{\text {polycrystal }}\right)}
\end{aligned}
$$

where $B=\left(C_{11}+2 C_{12}\right) / 3$ is the bulk modulus.

Fig. 4(a), 4(b), and 4(c) show the evolution as a function of temperature and plutonium content of Young's, shear, and bulk moduli, respectively. All moduli for all compositions decrease with increasing temperature. Between 300 and $1600 \mathrm{~K}$, the decrease seems to be linear for the three potentials, whereas at higher temperatures, they decrease more rapidly as per the recommendation. Moreover, the increment in the plutonium con- tent causes a moderate increase, of about $5 \%$, for the Arima and Postashnikov potentials and a moderate decrease, of about $5 \%$, for the Cooper potential for both the shear and Young's moduli. Even if the recommendation states that $(\mathrm{U}, \mathrm{Pu}) \mathrm{O}_{2}$ elastic constants should be taken identical to those of $\mathrm{UO}_{2}$, a moderate increase (about 3\%) with the addition of plutonium content is indicated by some authors $[49,50]$.

Comparing the different potentials, it appears clearly that the Arima potential gives the highest elastic constant overestimating largely the recommendation for the Young's modulus. The Potashnikov potential underestimates the Young's and shear moduli at low temperatures but fits well the recommendations around $2400 \mathrm{~K}$ up to melting point. The Cooper potential fits really well the recommendations over the full range of temperature. We recall here that the Cooper potential has been designed to reproduce the elastic constant of experimental data for single crystal. Furthermore, the correction for polycrystalline materials turns to be a good estimate.

Another important criterion is the anisotropy factor that reflects the difference of bonding with the different directions of the crystal. In cubic system the anisotropy can be quantified by the Zener's anisotropy factor defined as follow:

$$
Z=\frac{\left(2 C_{44}\right)}{\left(C_{11}-C_{12}\right)} .
$$

When $Z$ is equal to 1 , the system is perfectly isotropic, conversely a deviation from 1 shows that the system is anisotropic. We calculate the evolution for the three potentials of the Zener's factor as a function of the temperature for pure $\mathrm{UO}_{2}$ and pure $\mathrm{PuO}_{2}$. The crystals produced with the Arima and Cooper potentials are anisotropic for the full range of temperature $(Z \sim 0.5)$, whereas with the Potashnikov potential is isotropic at lower temperatures and becomes anisotropic around $2400 \mathrm{~K}$ where the Bredig's transition takes place for this potential. Therefore, one can expect a strong influence of the strain direction on the mechanical properties.

\subsection{Stress-strain curves}

In order to assess the empirical potentials on the cracking behaviour of $(\mathrm{U}, \mathrm{Pu}) \mathrm{O}_{2}$ solid solution, we carried out simulations to evaluate the stresses as a function of the strain for different plutonium contents and at different temperatures. The stressstrain curves are calculated by imposing an uniaxial deformation on the box with a constant strain rate $\left(10^{8} / \mathrm{s}\right)$ until the system cracks in two. During the simulation the stress component corresponding to the direction of deformation is recorded while relaxing the other components of the stress tensor under $\mathrm{N} \sigma \mathrm{T}$. In such a way, it is possible to investigate the anisotropy of the system.

We first check the stress-strain curves for the three main crystallographic directions of the fluorite crystal (i.e. $\langle 100\rangle,\langle 110\rangle$, and $\langle 111\rangle)$. The results for the three potentials at $300 \mathrm{~K}$ for pure $\mathrm{UO}_{2}$ and pure $\mathrm{PuO}_{2}$ are displayed in the Fig. 5. For all cases, the shapes of the stress-strain curves are consistent with a classical brittle fracture. Indeed, we observe a linear increase of the stress corresponding to the elastic deformation followed 

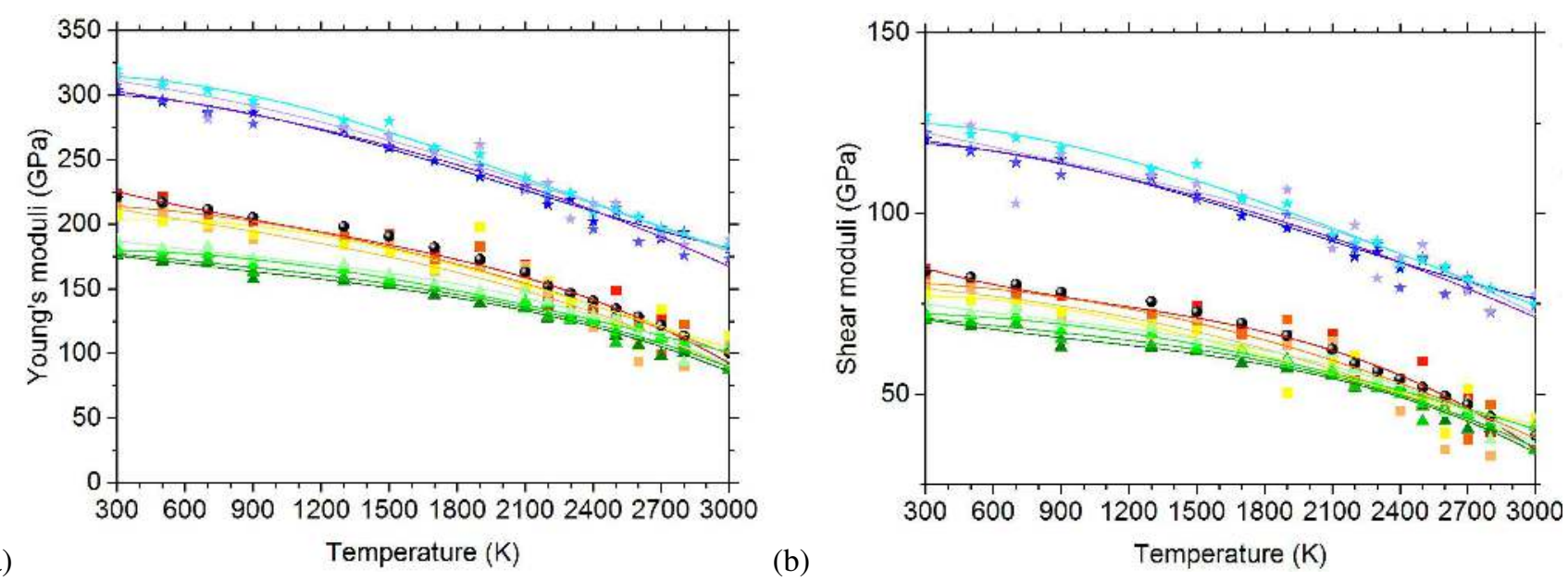

(a)

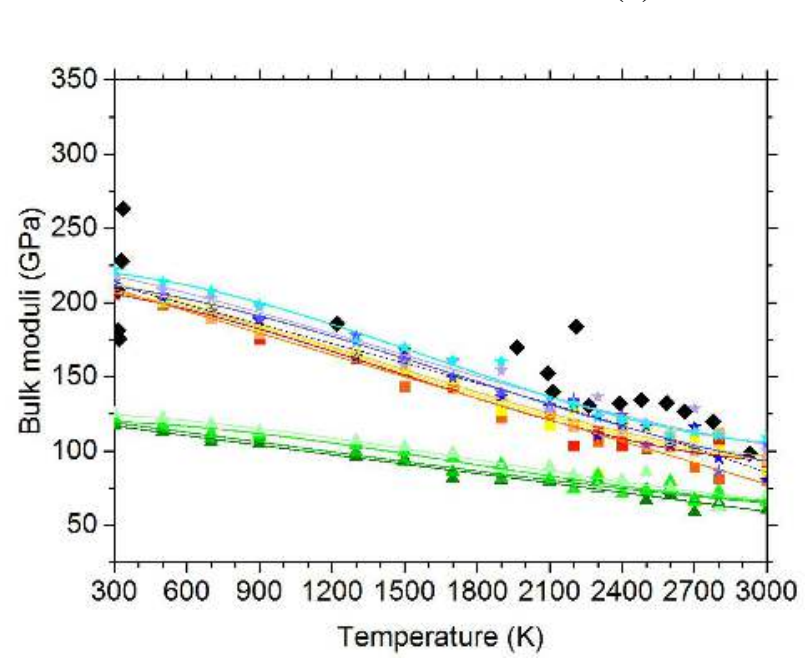

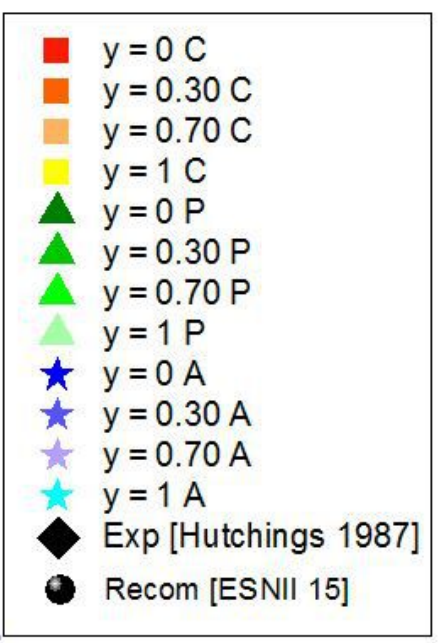

Figure 4: Evolution of Young's (a) shear (b) and bulk (c) polycrystalline moduli as a function temperature and plutonium content calculated with Arima, Potashnikov, and Cooper potentials (the value of y indicates the plutonium content, $\left.\left(\mathrm{U}_{1-y} \mathrm{Pu}_{y}\right) \mathrm{O}_{2}\right)$. (a) and (b) are compared with the recommendations in [26] and (c) is compared with experimental date of Hutchings et al. [48].

by an abrupt decrease indicating the loss of the crystal structure. The highest stress point is then defined as the ultimate tensile strength $\left(\sigma_{\text {UTS }}\right)$ at which the system begins to crack. For all the potentials the stiffest direction appears clearly to be the $\langle 100\rangle$ direction. The ultimate tensile strengths in the $\langle 110\rangle$ and $\left\langle\begin{array}{lll}1 & 1 & 1\rangle\end{array}\right\rangle$ directions are very close to each other in the case of the Arima and Potashnikov potentials. However, with the Cooper potential, $\sigma_{\text {UTS }}$ is slightly lower in the $\langle 1111\rangle$ direction. This in agreement with theoretical [41, 42] and experimental results $[43,44]$ that show that crack propagates mainly along the $\left\{\begin{array}{lll}1 & 1 & 1\end{array}\right\}$ planes. Therefore, for the rest of the investigation, we will only focus on the $\langle 111\rangle$ direction.

The impact of the temperature on $\sigma_{\text {UTS }}$ obtained from the stress-strain curves ranging from $300 \mathrm{~K}$ to the melting point for pure $\mathrm{UO}_{2}$ and pure $\mathrm{PuO}_{2}$ for the Arima, Potashnikov, and Cooper potentials is shown in Fig. 6.

The ultimate tensile strength decreases almost linearly as the temperature increases for all potentials. Also, there is no remarkable difference concerning the plutonium content. This is in agreement with recommendations found in the European
Commission state of art of MOX fuel report [2] in which it stats that the yield and ultimate stress for MOX are on a precautionary basis the same as $\mathrm{UO}_{2}$, whatever the $\mathrm{Pu}$ content, and up to $1500 \mathrm{~K}$. Our MD study suggests that this behaviour could be extrapolated to higher temperatures.

Another important thermo-mechanical property is the brittleto-ductile transition, which occurs at high temperature around half the melting point in both $\mathrm{UO}_{2}$ and $\mathrm{MOX}$ fuel $[51,52]$. This transition is defined as the temperature $\left(T_{C}\right)$ where yield stress and ultimate strength deviate from one another. Namely, below $T_{C}$ fuel behaviour is brittle whereas above $T_{C}$ fuel behaviour exhibits some plastic features. This temperature can be obtained as well from the stress-strain curves. In our simulations, yield stress is defined as the boundary in between elastic, reversible strain, and plastic, irreversible deformation using the following procedure. Regularly during the uniaxial deformation under tensile mode, the system is unloaded along the same direction until zero stress is reached. Then, the point where the resulting strain of the unloaded system is not equal to zero is taken as the yield stress. Hence, we can define a ratio between 
the yield stress and $\sigma_{\text {UTS }}$, which equals 1 at low temperature where the yield stress is combined with $\sigma_{\text {UTS }}$. The results of this ratio as a function of the temperature is reported in Fig. 7. For all the potentials, we find the same behaviour. As expected, from low temperatures up to around $1500 \mathrm{~K}$ for the Copper potential and around $1900 \mathrm{~K}$ for the Potashnikov and Arima potentials, yield stress and $\sigma_{\text {UTS }}$ are the same; the ratio is equal to 1. Above these temperatures, the ratio decreases rapidly until a plateau is reached. The transition between these two regimes is the brittle-to-ductile temperature. First, all potentials are able to reproduce this brittle-to-ductile behaviour. Cooper potential gives $T_{C}$ very close to the experimental value $(\sim 1673 \mathrm{~K}$ $[51,52])$ while the others overestimate it by about $300 \mathrm{~K}$. After the transition, the ratio stabilizes at $0.85,0.80$, and 0.75 for the Potashnikov, Arima, and Cooper potentials, respectively. This indicates that with the Cooper potential the material is inclined to experience plastic deformation for lower temperatures than with the other potentials.

However, conclusion about the reliability of the potentials based on this property needs to be taken with care. Indeed, the experimental values for the brittle-to-ductile transition are obtained from polycrystal samples and under strain rates far lower than the one of MD simulations. The physical phenomena underneath this transition are rather complex involving thermal creep which can not be captured by MD simulations. Therefore, the accuracy between MD and experiment could be a coincidence. Nonetheless, it still provides an indication on the behaviour at high temperatures.

To complete the assessment on the mechanical properties, we investigate crack propagation behaviour. The crack propagation simulations require large systems in order to include an initial crack and enough material to analyse its propagation. We use the thin strip geometry, where a constant strain is applied perpendicularly to the initial crack. The advantage of this geometry is that the energy release rate does not depend on the crack length, and can be found analytically by considering the energetics of an advancing crack. This is applicable if the system length (x-direction) to height (y-direction) ratio is at least 4 (i.e., $\mathrm{L}_{\mathrm{x}} \geq 4 \mathrm{~L}_{\mathrm{y}}$ ) [46, 47]. Therefore, we use a system including $4 \times 10^{6}$ atoms with initial box size roughly equal to $240 \times 60 \times 4 \mathrm{~nm}$ in the $\mathrm{x}, \mathrm{y}$, and $\mathrm{z}$ directions respectively. The initial notch is designed as an ellipse to ensure maximal stress concentration at the crack tip and equals $40 \times 10 \mathrm{~nm}$ in the $\mathrm{x}$ and y directions respectively. Such simulations are computationally expensive due to the size of the system. Therefore, only one simulation per interatomic potential is carried out. We choose a system with 25 at\% of plutonium at $300 \mathrm{~K}$ and the load is applied along the $\left\langle\begin{array}{llll}1 & 1 & 1\end{array}\right\rangle$ crystal orientation, which is considered the weakest. Loading is applied with constant strain-rate $\left(10^{8} / \mathrm{s}\right)$ until complete cracking of the system occurs. During the simulation, the stress tensor is recorded.

The mechanism of crack propagation can be determined by analysing the snapshots during the simulations. All the figures of these snapshots are shown in Fig. 8. Clear differences appear between the different potentials. For the Potashnikov potential, the crack propagates classically with cleavage-like behaviour, the crack opens straight with steady velocity. This behaviour is expected for a pure brittle material. Conversely, for the Arima and Cooper potentials the crack propagates at the interface or within a secondary phase that forms ahead of the crack tip. One can also observe small cavities forming which grow and coalesce with the main crack. This secondary phase (marked in grey colour in Fig. 8) is of rutile-like structure. In the case of Cooper potential, it covers relatively a large zone before crack actually opens up. This type of propagation denotes an unusual plastic-like behaviour at low temperature. However, the high strain-rate used here could cause to overestimate the stress field necessary for crack propagation and then the volume affected with the secondary phase. But, this phase transition ahead of crack tip has already been observed with MD simulations for pure $\mathrm{UO}_{2}$ with different interatomic potentials [41, 42].

Therefore, it is important for the potential assessment to check the relative stability of these phases to ensure that fluorite structure is the most stable phase for $(\mathrm{U}, \mathrm{Pu}) \mathrm{O}_{2}$ compounds. For this reason, we have undertaken energy-volume studies (not shown) with five different structures for both pure $\mathrm{UO}_{2}$ and pure $\mathrm{PuO}_{2}$. These structures are of type: fluorite $(\mathrm{F} m \overline{3} m)$, cotunnite $(\mathrm{P} n m a)$, rutile $\left(\mathrm{P}_{2} / m n m\right)$, scrutinyite $(\mathrm{P} b c n)$, and marcasite $(\mathrm{P} n n m)$. This study follows previous works in pure $\mathrm{UO}_{2}$ $[16,41,42]$ carried out with other empirical potentials and DFT calculations. We confirm that for both compounds the fluorite structure corresponds to the ground state for all three empirical potentials studied. As previously demonstrated with DFT calculations [41, 42, 45], we also find that cotunnite structure is the most stable at high isotropic pressure (compression) and that either rutile or scrutinyite structures are the most stable under negative isotropic pressure (tensile load in all the three directions). These two phases are almost energetically degenerate, hence it is impossible to distinguish which phase is the most favorable. Using the common tangent method, we calculate the transition pressures from fluorite structure to the other phases. These transition pressures are presented in Table 5 for both pure $\mathrm{UO}_{2}$ and pure $\mathrm{PuO}_{2}$. For all the potentials and pure $\mathrm{UO}_{2}$, the lowest transition pressure under tensile loading is found for the transition from fluorite to rutile structure, which is coherent with results of the crack propagation.

Table 5: Transition pressure at $T=0 \mathrm{~K}$ from fluorite structure to secondary phases in $\mathrm{GPa}$ for the three interatomic potentials for pure $\mathrm{UO}_{2}$ and pure $\mathrm{PuO}_{2}$. The negative sign denotes tensile loading.

\begin{tabular}{lcccccccc}
\hline \hline & \multicolumn{9}{c}{ Cluorite $(\mathrm{Fm} \overline{3} m)$ to } \\
& \multicolumn{2}{c}{$\begin{array}{c}c \\
\text { Rnmatile }\end{array}$} & \multicolumn{2}{c}{ Rcrutinyite } & \multicolumn{2}{c}{ Marcasite } \\
& $\mathrm{UO}_{2} / m n m$ & $\mathrm{PuO}_{2}$ & $\mathrm{UO}_{2}$ & $\mathrm{PuO}_{2}$ & $\mathrm{UO}_{2}$ & $\mathrm{PuO}_{2}$ & $\mathrm{UO}_{2}$ & $\mathrm{PuO}_{2}$ \\
\hline Arima & 44.3 & 106.9 & -8.3 & -9.3 & -9.6 & -7.4 & - & - \\
Potashnikov & 16.0 & 19.6 & -10.6 & -11.8 & -12.1 & -13.3 & - & -13.5 \\
Cooper & 3.0 & 4.0 & -6.8 & -10.3 & -8.0 & -8.2 & -16.0 & -15.8 \\
\hline \hline
\end{tabular}

The stress-strain curves calculated during the crack propagation are displayed in Fig. 9. The strain at which crack starts to propagate is different for the three potentials. Crack initiates first with the Potashnikov potential at around $4 \%$ followed by Arima at 5\% and finally Cooper at $6 \%$. However, the corresponding $\sigma_{\text {UTS }}$ is the highest for Arima potential at $10 \mathrm{GPa}$ followed by Cooper at $8 \mathrm{GPa}$, and Potashnikov at $5.5 \mathrm{GPa}$. These 
$\sigma_{\text {UTS }}$ are much lower than for the bulk case due to the presence of the initial crack, which concentrates the stresses at the crack tip. These values can also be related to the lower transition pressures in Table 5. For the Arima and Cooper potentials, $\sigma_{\text {UTS }}$ is greater than their relative transition pressure from fluorite to rutile structure. Therefore, the transition may occur at the crack tip where the stresses are the highest, explaining the plastic-like behaviour observed. However, it is noteworthy that these secondary phases are less stable than the fluorite structure and disappear behind the crack front as the crack advances. This could explain why this secondary phase cannot be directly observed experimentally. However, discrepancies between Griffith's theory and experimental results could be described by this behaviour [41]. Therefore, it is difficult to draw a conclusion about the accuracy of the empirical potentials for crack propagation.

\section{Conclusions}

In this paper, we assess empirical potentials for the $\left(\mathrm{U}_{1-y}, \mathrm{Pu}_{y}\right) \mathrm{O}_{2}$ solid solution. To date, only empirical potentials using rigid ion model are available. Since we are interested in studying for our future study on the mechanical behaviour under irradiation the point defects distribution, both cations need to be explicitly modeled. Therefore, we found in the literature five interatomic potentials fulfilling these requirements coined by the name for their first author: Yamada, Arima, Potashnikov, Tiwary, and Cooper. In our assessment, the structural (lattice parameter, relative phase stability) and thermodynamics (thermal expansion, Heat capacity) properties are systematically calculated for the full range of temperature from $300 \mathrm{~K}$ to melting point, and for the full range of plutonium content from pure $\mathrm{UO}_{2}$ to pure $\mathrm{PuO}_{2}$. We also investigate the potentials through their mechanical properties (elastic and crack propagation). Thus, this assessment includes ranges of temperatures and compositions as well as properties that have not been studied by the authors.

Tiwary potential turns quickly to be instable with MD simulation. Namely, the fluorite structure collapses after a few steps of simulation. Therefore, we eliminate this potential from our study. Yamada potential shows large discrepancies on the lattice parameter at high temperatures $(>2100 \mathrm{~K})$ with Fink's recommendation. Therefore, we also eliminate this potential from the rest of the assessment. For the three potentials remaining (i.e. Arima, Potashnikov, and Cooper), thermal expansion and heat capacity show good agreement up to $2000 \mathrm{~K}$. Nevertheless, at higher temperature with the Potashnikov and Cooper potentials so called $\lambda$-peaks appear, whereas no clear $\lambda$-peaks appears with the Arima potential up to $3000 \mathrm{~K}$. These peaks are usually associated with a superionic transition corresponding to the premelting of the oxygen atoms sublattice and have been observed experimentally around 0.8 of the melting point in $\mathrm{UO}_{2}$. The assessment shows as well that temperatures and the behaviour with plutonium content for the superionic transition seem better reproduced with the Cooper potential.

The mechanical elastic properties are also investigated as a function of temperature and plutonium content. The results show clearly that the elastic stiffness constants are best reproduced with the Cooper potential, which has been fitted on the elastic constant of experimental data for single crystal. The Potashnikov potential gives fairly good agreement with experimental data while Arima potential overestimates largely the elastic stiffness constants. However, anisotropy is present even at low temperature for the Cooper and Arima potentials whereas it appears only at high temperatures for Potashnikov potential. Hence, Cooper potential appears to be the best potential to reproduce the mechanical elastic properties.

Analysis of stress-strain curves obtained with uniaxial loading shows that the $\left\langle\begin{array}{llll}1 & 1 & 1\end{array}\right\rangle$ crystallographic direction gives lowest ultimate tensile strength, in agreement with experimental observations. We also find a brittle-to-ductile transition for the three potentials with transition temperature in good agreement with experimental values for Cooper potential and relatively close for the two others. Furthermore, all these mechanical properties show little dependence on the plutonium content, confirming the assumption that mechanical properties of $\mathrm{UO}_{2}$ can be, to a large extent, applied to MOX.

Finally, the behaviour during crack propagation simulations is very different between the three potentials. For the Cooper and Arima potentials the crack propagates through secondary phase of rutile-like structure that appears ahead of the crack tip leading to an unexpected plastic-like behaviour. Conversely, for Potashnikov potential crack propagates by cleavage, which is typical of a brittle-like behaviour. However, it is strenuous to conclude which potential reproduces best the reality since no direct experimental observation is available.

Overall, with the structural, thermodynamics, and mechanical properties assessment the Cooper interatomic potential reproduces the best the Fink's recommendation, yet it renders an unexpected plastic-like behaviour during crack propagation. The Potashnikov potential gives fairly good agreement for structural, thermodynamics, and elasticity properties. It also presents expected brittle behaviour during crack propagation. Finally, the Arima potential gives good results for structural and thermodynamics properties under $2100 \mathrm{~K}$, but presents discrepancies at high temperatures and gives average results for the mechanical properties.

\section{Acknowledgements}

This work was granted access to the HPC resources of [TGCC] under the allocation 2016-mtt7073 made by GENCI. This research contributes to the joint programme on nuclear materials (JPNM) of the European energy research alliance (EERA).

[1] S. Popov et al., Thermophysical Properties of MOX and $\mathrm{UO}_{2}$ Fuels Including the Effects of Irradiation, ONRL Rep., ORNL/TM- 2000/351, 2000.

[2] ESNII+ European commission. Deliverable D7.11 "state of the art with a literature review of MOX properties". (2015)

[3] K. Yamada, K. Kurosaki, M. Uno, S. Yamanaka, "Evaluation of thermal properties of mixed oxide fuel by molecular dynamics", J. Alloys Compd. 307 (2000) 1-9.

[4] K. Kurosaki, K. Yamada, M. Uno, S. Yamanaka, K. Yamamoto, T. Namekawa, "Molecular dynamics study of mixed oxide fuel", J. Nucl. Mater. 294 (2001) 160-167. 
[5] D. Terentyev, "Molecular dynamics study of oxygen transport and thermal properties of mixed oxide fuels", Computational Materials Science 40 (2007) 319-326.

[6] T. Arima, S. Yamasaki, Y. Inagaki, K. Idemitsu, "Evaluation of thermal properties of $\mathrm{UO}_{2}$ and $\mathrm{PuO}_{2}$ by equilibrium molecular dynamics simulations from 300 to 2000 K", J. Alloys Compd. 400 (2005) 43-50.

[7] T. Arima, S. Yamasaki, Y. Inagaki, K. Idemitsu, "Evaluation of thermal conductivity of hypostoichiometric $(\mathrm{U}, \mathrm{Pu}) \mathrm{O}_{2-x}$ solid solution by molecular dynamics simulation at temperatures up to $2000 \mathrm{~K}$ ", J. Alloys Compd. 415 (2006) 43-50.

[8] T. Arima, S. Yamasaki, K. Idemitsu, Y. Inagaki, "Equilibrium and nonequilibrium molecular dynamics simulations of heat conduction in uranium oxide and mixed uranium?plutonium oxide", J. Nucl. Mater. 376 (2008) 139-145.

[9] S. Nichenko, D. Staicu, "Molecular Dynamics study of the mixed oxide fuel thermal conductivity", J. Nucl. Mater. 439 (2013) 93-98.

[10] J. Ma, J. Zheng, M. Wan, J. Du, J. Yang, G. Jiang, ”Molecular dynamical study of physical properties of $\left(\mathrm{U}_{0.75} \mathrm{Pu}_{0.25}\right) \mathrm{O}_{2-x}$,, J. Nucl. Mater. 452 (2014) 230-234

[11] M.W.D. Cooper, S.C. Middleburgh, R.W. Grimes, "Modelling the thermal conductivity of $\left(\mathrm{U}_{x} \mathrm{Th}_{1-x}\right) \mathrm{O}_{2}$ and $\left(\mathrm{U}_{x} \mathrm{Pu}_{1-x}\right) \mathrm{O}_{2}$ ", J. Nucl. Mater. 466 (2015) 29-35.

[12] W. Li, J. Ma, J. Du, G. Jiang, "Molecular dynamics study of thermal conductivities of $\left(\mathrm{U}_{0.7-x} \mathrm{Pu}_{0.3} \mathrm{Am}_{x}\right) \mathrm{O}_{2}$ ", J. Nucl. Mater. 480 (2016) 47 51.

[13] K. Govers, S. Lemehov, M. Hou, M. Verwerft, "Comparison of interatomic potentials for $\mathrm{UO}_{2}$. Part I: Static calculations", J. Nucl. Mater. 366 (2007) 161-177.

[14] K. Govers, S. Lemehov, M. Hou, M. Verwerft, "Comparison of interatomic potentials for $\mathrm{UO}_{2}$. Part II: Molecular dynamics simulations", J. Nucl. Mater. 376 (2008) 66-77.

[15] S.I. Potashnikov, A.S. Boyarchenkov, K.A. Nekrasov, A.Ya Kupryazhkin, "High-precision molecular dynamics simulation of $\mathrm{UO}_{2}-\mathrm{PuO}_{2}$ : Pair potentials comparison in $\mathrm{UO}_{2}$ ", J. Nucl. Mater. 419 (2011) 217-225.

[16] A. Chernatynskiy, C. Flint, S.B. Sinnott, S.R. Phillpot, "Critical assessment of $\mathrm{UO}_{2}$ classical potentials for thermal conductivity calculations", J. Mater. Sci. 47 (2012) 7693-7702.

[17] C.B. Basak, A.S. Kolokol, "A Novel Pseudo-Ion Approach in Classical MD Simulation: A Case Study on $\left(\mathrm{U}_{0.8} \mathrm{Pu}_{0.2}\right) \mathrm{O}_{2}$ Mixed Oxide", J. am. Ceram. Soc. 95 (2012) 1435-1439.

[18] P. Tiwary, A. van de Walle, B. Jeon, and N. Grønbech-Jensen, "Interatomic potentials for mixed oxide and advanced nuclear fuels", Phys. Rev. B 83 (2011) 094104.

[19] M.W.D. Cooper, M.J.D. Rushton, and R.W. Grimes, ”A many-body potential approach to modelling the thermomechanical properties of actinide oxides", J. Phys. Condens. Matter. 26 (2014) 105401.

[20] M.W.D. Cooper, S.T. Murphy, M.J.D. Rushton, R.W. Grimes, "Thermophysical properties and oxygen transport in the $\left(\mathrm{U}_{x}, \mathrm{Pu}_{1-x}\right) \mathrm{O}_{2}$ lattice", $\mathrm{J}$. Nucl. Mater. 461 (2015) 206-214.

[21] J.D. Axe, "Long-Wave Lattice Dynamics of the Fluorite Structure", Phys. Rev. 139. (1965) A1215-1220.

[22] http://lammps.sandia.gov/

[23] M. Parrinello and A. Rahman, "Polymorphic transitions in single crystals: A new molecular dynamics method", J. Appl. Phys. 52 (1981) 7182-7190.

[24] R.C. Belin, M. Strach, T. Truphémus, C. Guéneau, J.C. Richaud, J. Rogez, "In situ high temperature X-Ray diffraction study of the phase equilibria in the $\mathrm{UO}_{2}-\mathrm{PuO}_{2}-\mathrm{Pu}_{2} \mathrm{O}_{3}$ system", J. Nucl. Mater. 465 (2015) 407-417.

[25] T. Yamashita, N. Nitani, T. Tsuji, H. Inagaki, "Thermal expansions of $\mathrm{NpO}_{2}$ and some other actinide dioxides”, J. Nucl. Mater. 245 (1997) 72 78.

[26] J. Fink, J. Nucl. Mater. 279 (200) 1-18; IAEA-TECDOC-1496 , "Thermophysical properties database of (materials for light water reactors and heavy water reactors"

[27] E.R. Gardner, T.L. Markin, and R.S. Street, "The plutonium-oxygen phase diagram", J. Inorg. NucJ. Chem. 27 (1965) 541-551.

[28] T. Uchida, T. Sunaoshi, K. Konashi, M. Kato, "Thermal expansion of $\mathrm{PuO}_{2}$ ", J. Nucl. Mater. 452 (2014) 281-284.

[29] A.S. Dworkin and M.A. Bredig, "Diffuse Transition and Melting in Fluorite and Anti-Fluorite Type of Compounds: Heat Content of Potassium Sulfide from 298 to 1260 K", J. Phys. Chem. 72 (1968) 1277-1281.
[30] J. Ralph, "Specific Heat of $\mathrm{UO}_{2}, \mathrm{Tho}_{2}, \mathrm{PuO}_{2}$, and the Mixed Oxides $\left(\mathrm{Th}_{x} \mathrm{U}_{1-x}\right) \mathrm{O}_{2}$, and $\left(\mathrm{Pu}_{0.2} \mathrm{U}_{0.8}\right) 0_{1.97}$ by Enthalpy Data Analysis", J. Chem. Soc., Faraday Trans. 283 (1987) 1253-1262.

[31] C. Ronchi and G.J. Hyland, "Analysis of recent measurements of the heat capacity of uranium dioxide ", J. Alloys Compd. 213 (1994) 159-168

[32] E. Yakub, C. Ronchi, and D. Staicu, "Molecular dynamics simulation of premelting and melting phase transitions in stoichiometric uranium dioxide", J. Chem. Phys. 127 (2007) 094508.

[33] A. Lunev and B. Tarasov, "A classical molecular dynamics study of the correlation between the Bredig transition and thermal conductivity of stoichiometric uranium dioxide", J. Nucl. Mater. 415 (2011) 217-221.

[34] M.A. Korneva and S.V. Starikov, "Atomistic Simulation of a Superionic Transition in $\mathrm{UO}_{2}$ ", Phys. of Solid State 58 (2016) 177-182.

[35] J.P. Hiernaut, G.J. Hyland, C. Ronchi, "Premelting Transition in Uranium Dioxide”, Int. J. Thermophys. 14 (1993) 259-283.

[36] R. Böhler, M.J. Welland, D. Prieur, P. Cakir, T. Vitova, T. Pruessmann, I. Pidchenko, C. Hennig, C. Guéneau, R.J.M. Konings, D. Manara, ’Recent advances in the study of the $\mathrm{UO}_{2}-\mathrm{PuO}_{2}$ phase diagram at high temperatures", J. Nucl. Mater. 448 (2014) 330-339.

[37] D.G. Martin, 'The elastic constants of polycrystalline $\mathrm{UO}_{2}$ and (U, Pu) mixed oxides: a review and recommendations", High Temperatures-High Pressures 21 (1989) 13-24.

[38] R. Hill, "The Elastic Behaviour of a Crystalline Aggregate", Proc. Phys. Soc. A 65 (1952) 349-352.

[39] M. Mehl et al., in: J.H. Westbrook, R.L. Fleischeir (Eds.), Intermetallic Compounds: Principle and Practice, vol. I: Principles, John Wiley and Sons, London, 1995, pp. 195-210, Chapter 9

[40] E. Schreiber et al., Elastic Constants and Their Measurement, McGraham Hill, New York, 1973

[41] Y. Zhang, X.Y. Liu, P.C. Millett, M. Tonks, D.A. Andersson, B. Biner, "Crack tip plasticity in single crystal $\mathrm{UO}_{2}$ : Atomistic simulations", J. Nucl. Mater. 430 (2012) 96-105

[42] P. Fossati, L. Van Brutzel, A. Chartier, and J.P. Crocombette, "Simulation of uranium dioxide polymorphs and their phase transitions", Phys. Rev. B 88 (2013) 214112

[43] E.J. Rapperport and A.M. Huntress, "Deformation modes of single crystal uranium dioxide from $700^{\circ} \mathrm{C}$ to $1900^{\circ} \mathrm{C}$.", NMI-1242 Metallurgy and ceramics (1960)

[44] R.G. Robins and P.J. Baldock, "Uranium Oxide Cleavage", J. Am. Ceram. Soc. 43 (1960) 228

[45] T.G. Desai and B.P. Uberuaga, "Stress-induced phase transformation in nanocrystalline $\mathrm{UO}_{2}$ ", Scripta Materialia 60 (2009) 878 ?881.

[46] M.J. Buehler, F.F. Abraham, H. Gao, "Hyperelasticity governs dynamic fracture at a critical length scale", Nature 426 (2003) 141-146.

[47] W.C. Knauss, "Stresses in an Infinite Strip Containing a Semi-Infinite Crack", J. Appl. Mech. 33 (1966)356-362.

[48] M.T. Hutchings, "High-temperature studies of UO2 and ThO2 using neutron scattering techniques", J. Chem. Soc., Faraday Trans. 2, 83 (1987), 1083-1103.

[49] C.H. de Novion, B. Amice, A. Groff, Y. Guerin, A. Padel, "Mechanical Properties of Uranium Plutonium Based Ceramics", Nucl. Metall. 17 (1970) 509-517.

[50] A.W. Nutt Jr., A.W. Allen, J.H. Handwerk, "Elastic and Anelastic Response of Polycrystalline $\mathrm{UO}_{2}-\mathrm{PuO}_{2}$ ", J. Am. Ceram. Soc. 53 (1970) 205-209.

[51] J.T.A. Roberts and B.J. Wrona, "Nature of brittle-to-ductile transition in $\mathrm{UO}_{2}-20 \mathrm{wt} \% \mathrm{PuO}_{2}$ nuclear fuel", J. Nucl. Mater. 41 (1971) 23-38.

[52] J.T.A. Roberts, "Brittle fracture of oxide nuclear fuel", J. Nucl. Mater. 47 (1973) 125-128 


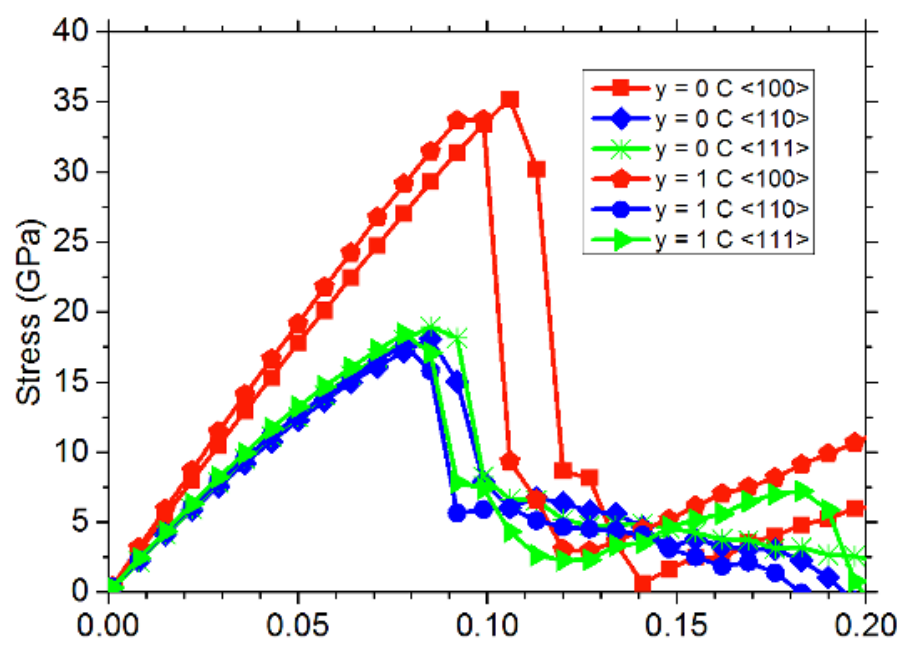

(a)

Strain

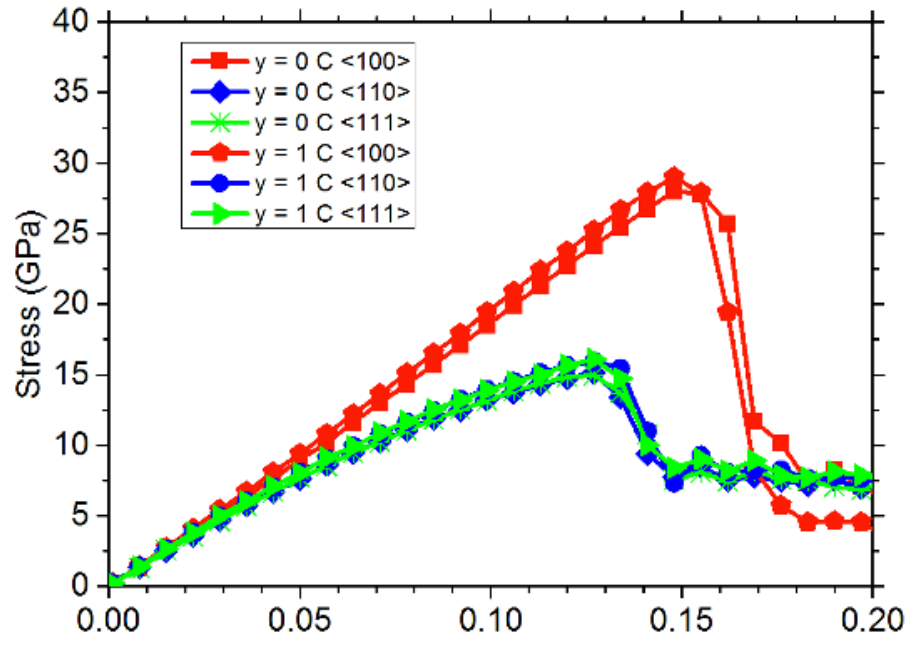

(b)

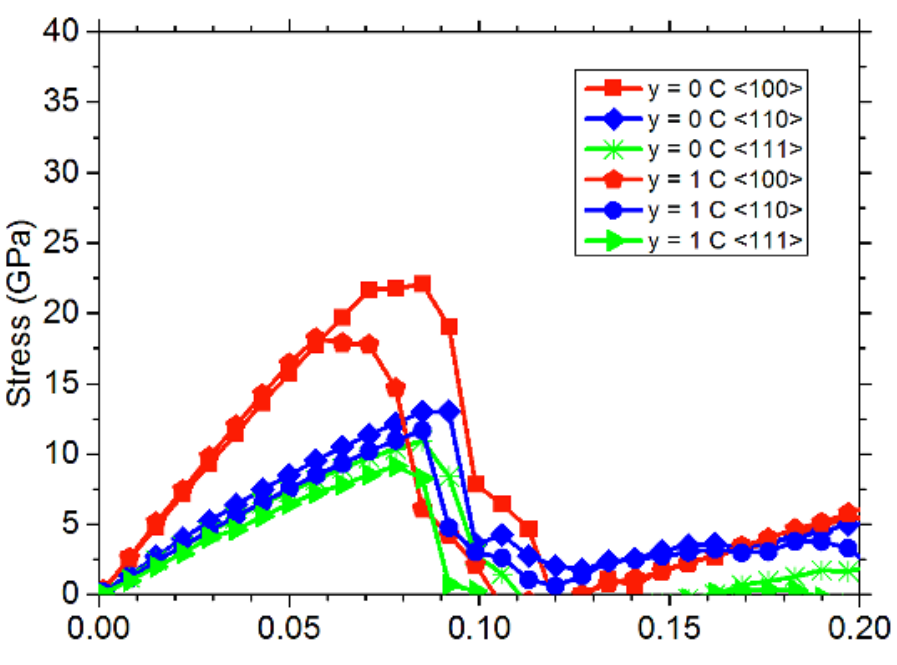

(c)

Strain

Figure 5: Stress-strain curves for the three interatomic potentials ((a) Arima, (b) Potashnikov, and (c) Cooper) at $300 \mathrm{~K}$ strained in the main three crystallographic directions of the fluorite crystal (i.e. $\langle 100\rangle,\langle 110\rangle$, and $\langle 111\rangle$ ). For each potential, it is shown the results for pure $\mathrm{UO}_{2}$ and pure $\mathrm{PuO}_{2}$. 


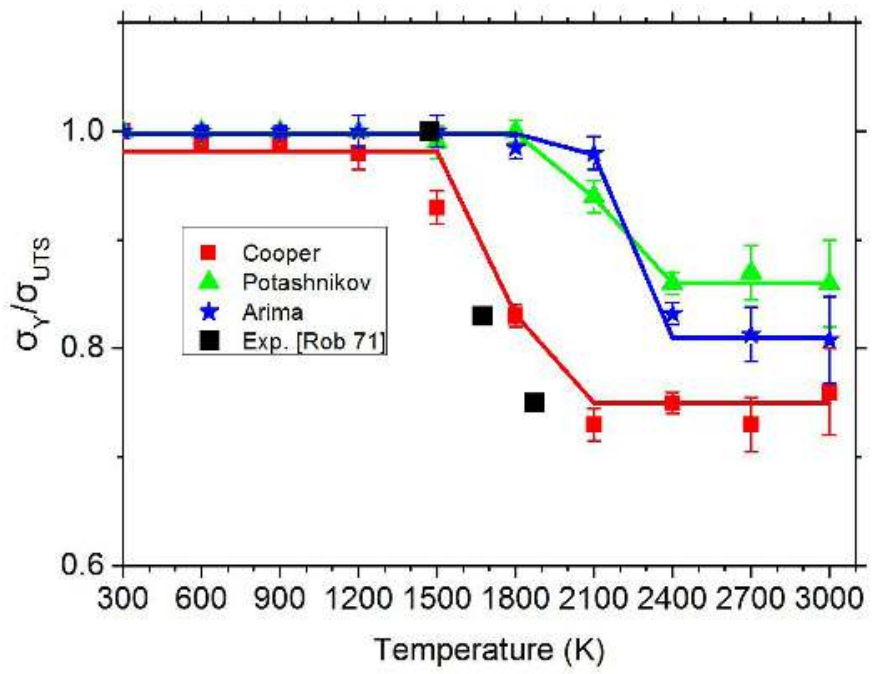

Figure 6: Evolution of the ultimate tensile strength as a function of the temperature and plutonium content (the value of y indicates the plutonium content, $\left.\left(\mathrm{U}_{1-y} \mathrm{Pu}_{y}\right) \mathrm{O}_{2}\right)$

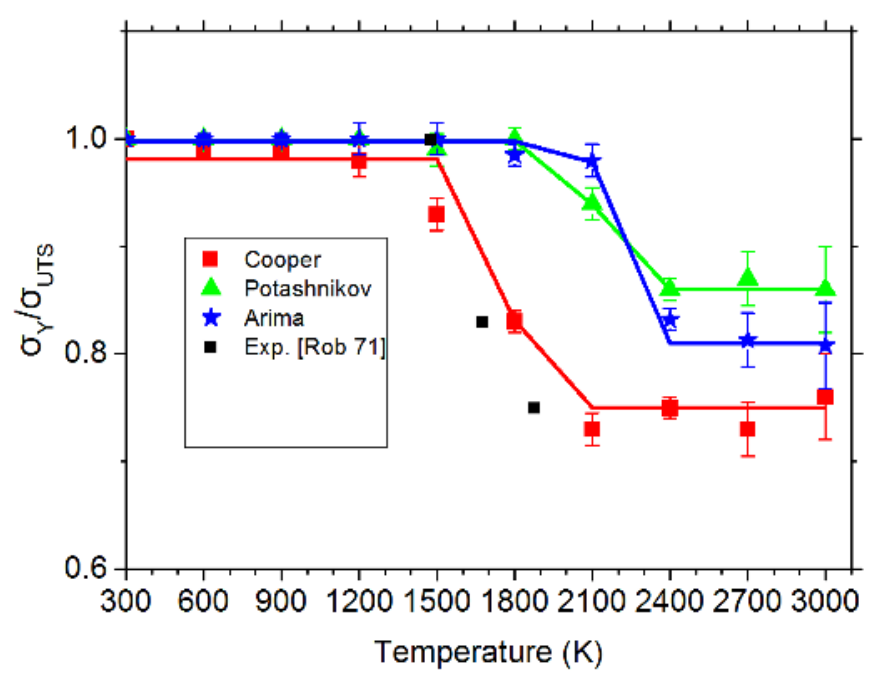

Figure 7: Ratio between the Yield stress and the ultimate tensile strength $\left(\sigma_{\text {Yield }} / \sigma_{\text {UTS }}\right)$ as a function of temperature. These values are compared with experimental data found in [51]. 

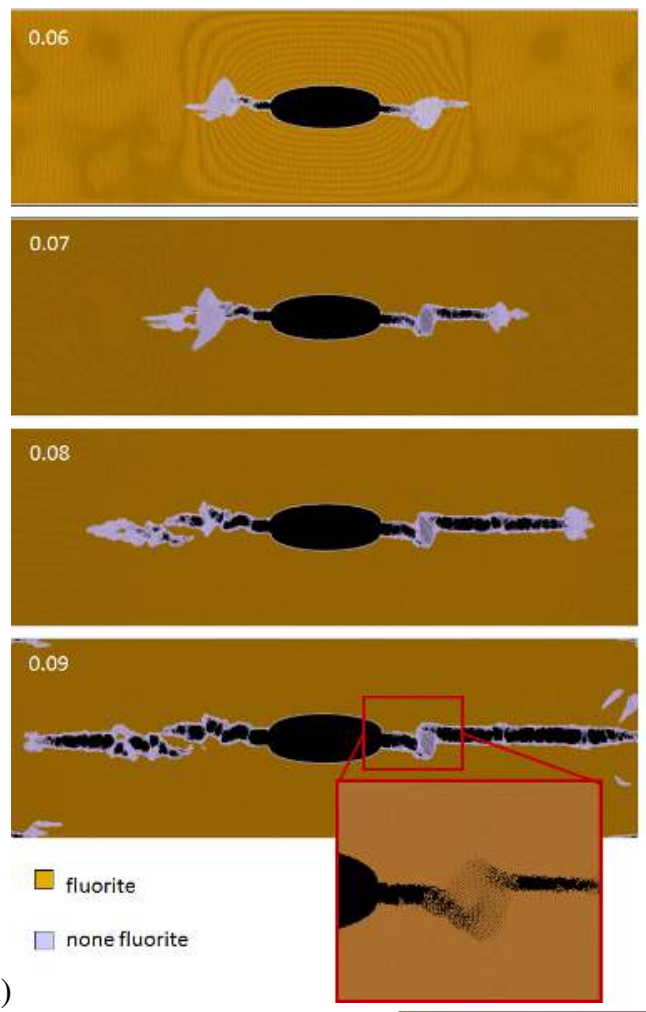

(a)
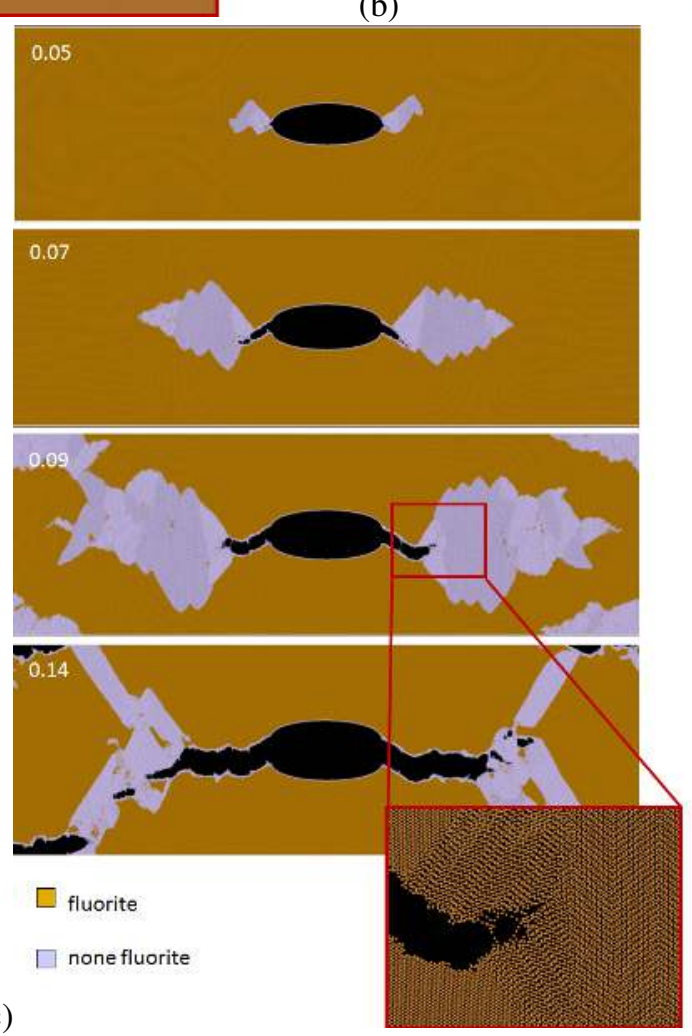

(c)

Figure 8: Snapshots during crack propagation in $(\mathrm{U}, \mathrm{Pu}) \mathrm{O}_{2}$ system with 25 at.\% of plutonium at $300 \mathrm{~K}$ for (a) Arima, (b) Potashnikov, and (c) Cooper potentials. The load is applied along the $\left\langle\begin{array}{lll}1 & 1 & 1\end{array}\right\rangle$ crystallographic direction in the fluorite structure. The inserts in each figure depict a close up of the crack front where phase transition occurs.
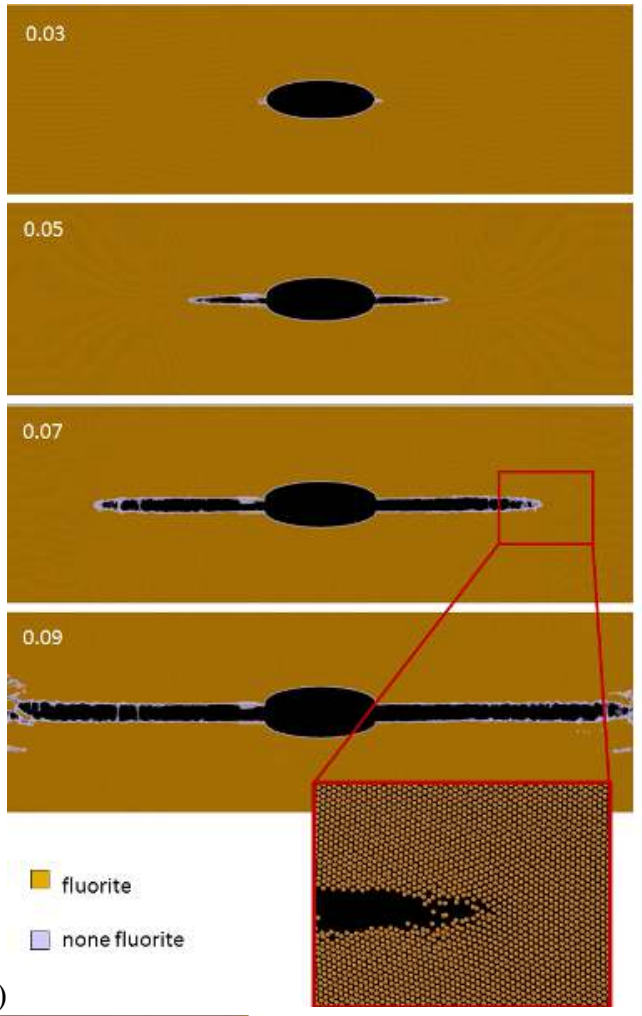

b) 


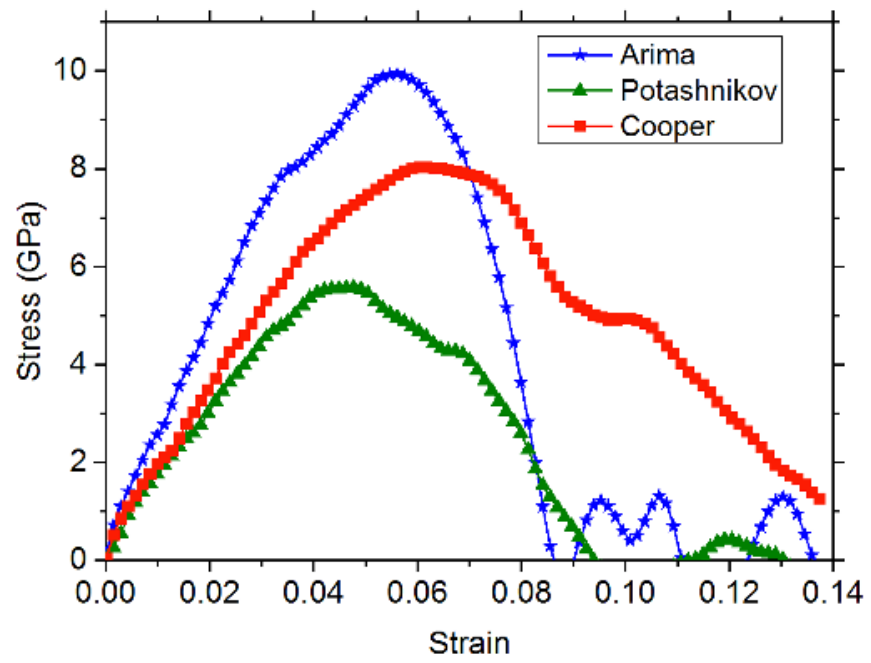

Figure 9: Stress-strain curves for the three interatomic potentials during crack propagation in $(\mathrm{U}, \mathrm{Pu}) \mathrm{O}_{2}$ system with 25 at. $\%$ of plutonium at $300 \mathrm{~K}$. The load is applied along the $\langle 111\rangle$ crystallographic direction in the fluorite structure. 